\title{
Orientação sexual e seus efeitos no mercado de trabalho: um estudo com base na técnica de revisão sistemática*
}

\author{
Daniel Suliano** \\ Guilherme Irffi* ${ }^{\star \star \star}$

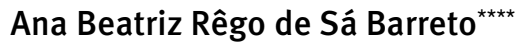

\begin{abstract}
Ao fazer uso da técnica de revisão sistemática, este trabalho apresenta dois objetivos. Em primeiro lugar, procurou-se identificar por meio da literatura especializada diferentes formas de classificação da orientação sexual no âmbito do mercado de trabalho. Tendo em vista o segundo objetivo, analisou-se o mercado de trabalho como um canal que gera distribuição desigual de renda mediante mecanismos discriminatórios a partir dos diferenciais de rendimentos com base na orientação sexual. A fonte de dados utilizada foi a plataforma Periódicos Capes. Entre os resultados, quatro formas de identificação da orientação sexual foram observadas, tendo as uniões consensuais (coabitação) o maior número de estudos, seguidas da autodeclaração, comportamento e militância. Adicionalmente, pode-se destacar a penalidade salarial sofrida por homens gays vis-à-vis as suas contrapartes sexuais, prêmio salarial para lésbicas, com relação às mulheres heterossexuais, e desvantagens dos homossexuais na inserção do mercado de trabalho em simulações na taxa de convite para entrevista, revelando, assim, indícios de discriminação logo na etapa inicial de contratação. Finalmente, é ressaltado que, mesmo na presença de legislações que protejam minorias sexuais, até em países mais liberais e tolerantes, o ambiente profissional não está completamente alinhado à produtividade do trabalhador.
\end{abstract}

Palavras-chave: Mercado de trabalho. Orientação sexual. Homossexual.

\footnotetext{
* Agradecemos aos três pareceristas anônimos e aos editores da Rebep, Paula Miranda-Ribeiro e Roberto Nascimento Rodrigues, pelos comentários e sugestões úteis. Também agradecemos aos comentários e sugestões de Jaime Jesus Filho, aos feedbacks recebidos durante as conferências e apresentações (Abep 2019 e Abet 2019). Este estudo foi financiado pelo CNPq, por meio da Chamada Universal CNPq/MCTI no 01/2016, Processo n- 406564/2016-7. As opiniões expressas neste documento são dos autores e não refletem necessariamente as opiniões de qualquer uma das instituições às quais são afiliados.

** Instituto de Pesquisa e Estratégia Econômica do Ceará (Ipece), Fortaleza-CE, Brasil (daniel.suliano@ipece.ce.gov.br; https://orcid.org/0000-0002-6550-6139).

${ }_{\star \star \star \star}$ Universidade Federal do Ceará (UFC), Fortaleza-CE, Brasil, (irffi@caen.ufc.br; https://orcid.org/0000- 0002-3558-7628).

${ }^{* \star \star \star}$ Grupo Fleury, São Paulo-SP, Brasil (abeatrizrsb@gmail.com; https://orcid.org/0000-0002-8526-7526).
} 


\section{Introdução}

Estudos teóricos e aplicados no âmbito do mercado de trabalho têm sido desenvolvidos com base na existência de desigualdade entre sexo, raça e naturalidade. Mais recentemente, alterações de paradigmas, no que tange à orientação sexual, vêm redefinindo as estruturas familiares e alocando mais atenção a problemas de inclusão social dessas minorias, tornando esse um tema de discussão global.

De fato, o modelo de "família normal" - de um pai provedor, mãe dona de casa e filhos - não corresponde ao padrão predominante no arranjo doméstico contemporâneo, no Brasil e em outras partes do mundo, tendo como destaque os modelos "desviantes" representados por uniões de pessoas do mesmo sexo (ALVES; CAVENAGHI; BARROS, 2010). Adicionalmente, mudanças demográficas e sociais vêm impactando diretamente na composição familiar e no tamanho dos domicílios, ocasionando menor quantidade de filhos, crescimento de casais que optam por não ter prole, aumento de divórcios e separações, recasamentos e maior quantitativo de pessoas que moram sozinhas (CAMARANO; FERNANDES, 2014).

Outras mudanças no aspecto jurídico-institucional relacionadas aos homossexuais foram substanciais. Em 1989, a Dinamarca se tornou o primeiro país a reconhecer, legalmente, uniões de pessoas do mesmo sexo. No Reino Unido, a incorporação em lei da Convenção Europeia dos Direitos do Homem e a entrada em vigor do Tratado de Amsterdã de 1999 introduziram explicitamente a categoria orientação sexual no direito internacional (CALANDRINO, 1999). Na Holanda, em 1998, houve o reconhecimento da união civil entre os homossexuais e aprovação do casamento em 2001 pelo Parlamento (TRANDAFIR, 2012). Em 1996, o Canadá aprovou uma lei antidiscriminação em prol de minorias sexuais, tendo, em julho de 2005, legalizado o casamento entre pessoas do mesmo sexo (DILMAGHANI, 2007). ${ }^{1}$

Não obstante esses avanços na proteção legislativa, minorias sexuais ainda declaram maiores obstáculos na obtenção de emprego, menor satisfação no trabalho, mais bullying e assédio do que suas contrapartes heterossexuais, o que necessita, seguramente, de outras intervenções políticas (DRYDAKIS, 2014b).

Diante desse contexto, o presente trabalho utiliza a técnica de revisão sistemática para alcançar dois objetivos. 0 primeiro visa identificar, por meio da literatura especializada, diferentes formas de classificação da orientação sexual. Tendo em vista o primeiro objetivo, o segundo consiste em investigar como a literatura analisa o mercado de trabalho, a partir dos diferenciais de rendimentos, além da oferta de trabalho, a alocação de tempo entre atividade doméstica e de mercado, discriminação, ocupação, bem-estar, entre outras.

Uma das hipóteses engendradas, a partir desse segundo objetivo, é de que o mercado de trabalho atua como um canal que gera distribuição desigual de renda mediante

\footnotetext{
${ }^{1}$ No Brasil, em 2011, o Supremo Tribunal Federal também reconheceu a união civil entre pessoas do mesmo sexo (BRASIL, 2011).
} 
mecanismos discriminatórios baseados na orientação sexual, não obstante a ocupação idêntica de postos de trabalho por pessoas de mesmo nível de capital humano e produtividade. $^{2}$

Entre os resultados, quatro formas de identificação da orientação sexual foram observadas, tendo as uniões consensuais (coabitação) ${ }^{3}$ o maior número de estudos, com um total de 22. Uma segunda forma de identificação verificada foi a partir de perguntas diretas a adultos, conhecida na literatura como autodeclaração. A terceira identificação se deu por meio do comportamento e experiências sexuais. Por fim, é possível simular um processo de contratação em que se distingue, de modo implícito, a orientação sexual pelo envio de currículos a empresas. Outros resultados encontrados foram: penalidade salarial sofrida por homens gays vis-à-vis as suas contrapartes sexuais; diferencial salarial a favor das lésbicas; e desvantagens na tentativa de inserção, no mercado de trabalho, a partir da taxa de convite para entrevista dos identificados como homossexuais, revelando, assim, indícios de discriminação logo na etapa inicial de contratação.

Para alcançar os objetivos citados, o artigo foi estruturado em cinco seções, incluindo esta introdução. Na seção subsequente, é feita uma breve revisão da literatura no que concerne à desigualdade salarial de gênero no mercado de trabalho concatenado ao debate da orientação sexual. Posteriormente, são introduzidos o conceito de revisão sistemática e os critérios utilizados para seleção dos artigos. Analisam-se as diferentes formas de identificação da orientação sexual e discorre-se sobre os diferenciais salariais no mercado de trabalho. Por fim, são tecidas as considerações finais.

\section{A desigualdade salarial de gênero e o início do debate da orientação sexual}

No âmbito do gênero, muita embora a elevação da escolaridade, a queda da fertilidade e as mudanças tecnológicas - que afetaram a produção doméstica - tenham alterado o padrão de oferta de mão de obra feminina, fatores eminentemente econômicos, como o aumento do salário real, tiveram impacto significativo na força de trabalho mediante maior

\footnotetext{
${ }^{2}$ Características natas como raça, gênero e habilidades cognitivas (inteligência e esforço, por exemplo) e não cognitivas podem também ser causa de distribuição desigual de renda. As duas primeiras são mecanismos discriminatórios, enquanto as habilidades cognitivas são prêmios que o mercado de trabalho reconhece como meritórios. Adicionalmente, características como capital humano, experiência profissional e tenure podem também ser canais de desigualdade salarial, além de riqueza inicial e desigualdade de oportunidades. No caso dessas três primeiras fontes, o mercado de trabalho acaba sendo um mecanismo revelador, enquanto para as duas últimas ele acaba sendo um elemento gerador de desigualdade.

${ }^{3}$ Lesthaeghe e Van de Kaa (1986) chamam atenção para o surgimento de novos arranjos de casamento a partir da década de 1970. Com efeito, essa é uma das características da segunda transição demográfica (STD), em que, além da diminuição dos casamentos formais, ocorreram "dessacramentação" dos matrimônios, aumento da idade ao casar, autonomia das mulheres, aumento do número de divórcios, separações, recasamentos e não casamentos e taxa de fecundidade abaixo do nível de reposição, sendo essa última a principal característica (CAMARANO; FERNANDES, 2014). Destaca-se também uma desconexão entre casamento e procriação e nenhuma população estacionária (LESTHAEGHE; SURKYM, 1988; LESTHAEGHE, 1995). Em Lesthaeghe (2014), é observada uma visão geral do conceito de STD desde 1986, abordando componentes e a aplicabilidade da STD formulado por Lesthaeghe e Van de Kaa (1986). Por fim, ressalta-se que, desde a segunda metade do século XX, o processo de constituição de famílias tem experimentado transformações expressivas nos países desenvolvidos e naqueles em desenvolvimento. Dentre os novos padrões surgidos, é observado o aumento da coabitação e dos casamentos homossexuais (CAMARANO, 2014).
} 
participação de mulheres casadas, a partir da década de 1950. Até então, ao longo de todo o século XIX até meados do século XX, predominavam políticas declaradamente restritivas em empresas, distritos escolares e, mesmo dentro de governos, restrições quanto à contratação de mulheres após o casamento em certos segmentos do mercado de trabalho americano (GOLDIN, 1990).

No Brasil, as décadas de 1980 e 1990 foram de grandes transformações no mercado de trabalho, por conta do forte aumento da taxa de participação feminina na força de trabalho, principalmente para as coortes mais novas e para as mulheres com 1 a 11 anos de estudos (SCORZAFAVE; MENEZES FILHO, 2001), isto é, com educação básica; além de uma maior contribuição dos seus rendimentos para a renda domiciliar nos estratos intermediários (HOFFMANN; LEONE, 2004).

Avanços atuais na literatura internacional vêm revelando resultados surpreendentes no que tange à igualdade de gênero no mercado de trabalho. No caso, não são as soluções convencionais, como intervenções governamentais e maiores responsabilidades dos homens em casa, que irão reduzir, ou até desaparecer, o hiato na remuneração de homens e mulheres, mas sim um incentivo para recompensar desproporcionalmente indivíduos que trabalham longas horas e horários específicos. Assim, o "último capítulo" na convergência de rendimentos entre os gêneros envolve alteração na estrutura dos empregos e flexibilidade na jornada de trabalho, instrumentos que fazem parte de setores de rápido crescimento, como os de tecnologia da informação (GOLDIN, 2014).

De fato, os avanços dos serviços de plataformas digitais a partir da "economia gig" vêm alterando as estruturas do mercado de trabalho por meio da maior flexibilidade e realocação das horas de trabalho. A análise da oferta de trabalho, entre mais de um milhão de motoristas no aplicativo Uber dos Estados Unidos, encontrou ganhos para homens de cerca de $7 \%$ a mais por hora com relação às mulheres por conta de diferenciais compensatórios (homens tendem a dirigir em locais mais lucrativos), experiência acumulada de trabalho e velocidade média mais alta. Como no Uber não há negociação salarial, similar a outras economias do tipo "gig”, a discriminação do cliente à lá Becker (1957) ${ }^{4}$ passa a não ser materialmente importante (COOK et al., 2018).

Na temática orientação sexual e identidade de gênero, a Organização das Nações Unidas (ONU) fez referência ao tema apenas na década de 1980, relacionando a pandemia de HIV/Aids com a homossexualidade. Já em termos de luta pelos direitos humanos LGBT, o fato conhecido como Stonewall Uprising, em 1969, é considerado o marco inicial (GORISCH, 2014).

Alguns avanços foram observados a partir do compromisso da ONU em reconhecer as minorias sexuais e permitindo ajuste às suas demandas à luz do direito internacional (NAGAMINE, 2019). No entanto, deve-se destacar que, mesmo antes desses avanços, boas

\footnotetext{
${ }^{4}$ Em Becker (1957), o principal tipo de discriminação ocorre quando consumidores preferem trabalhadores com determinada característica.
} 
práticas no que diz respeito aos direitos da comunidade LGBT já ocorriam. De fato, em 1933, a prática homossexual já não era considerada crime na Dinamarca (OLSEN, 2015).

Mesmo assim, isso não deixa de ser contrastante com práticas homofóbicas desenvolvidas desde o final do século XIX na história ocidental, problematização que teria provocado surpresa aos antigos gregos ou romanos (BORRILLO, 2010).

Em estudos acadêmicos, analisar diferenciais salariais no âmbito do mercado do trabalho tem sido um desafio não somente por conta da escassez de base de dados, mas também pela dificuldade em identificar a orientação sexual dos indivíduos. No estudo pioneiro que analisou diferencial de salários entre homossexuais e heterossexuais, foi necessário utilizar um empilhamento (pooling) da base de dados de diferentes anos, a fim de obter representatividade amostral de gays e lésbicas (BADGETT, 1995).

Como aponta Drydakis (2014b), as pessoas se sentem desconfortáveis em discutir orientação sexual em entrevistas, tendo esse comportamento influência direta nas estimativas e levando, por conseguinte, a informações falsas ou mesmo ausência de dados. Ademais, funcionários mais bem estabelecidos nos empregos e com maiores ganhos podem ser os mais inclinados a revelarem sua orientação sexual, resultando em um número proporcionalmente maior desse grupo em termos de representatividade amostral.

\section{Metodologia}

A revisão sistemática pode ser entendida como uma forma de pesquisa que utiliza como fonte de dados a literatura sobre determinado tema (SAMPAIO; MANCINE, 2007). Pode-se também conceituar revisões sistemáticas como ferramentas de investigação que permitem obter evidências a partir de uma gama de resultados de pesquisas. Por isso, o uso desse método tende a contribuir para a tomada de decisões, pois sumariza a literatura a partir de um planejamento sistematizado, ${ }^{5}$ em que são definidos critérios para cada etapa da investigação com o objetivo de minimizar erros aleatórios ou sistemáticos dos resultados. Além disso, é necessário elaborar uma estratégia de busca, estabelecer critérios de elegibilidade e analisar a qualidade metodológica dos dados - empregando estudos originais com sua população (BERWANGER et al., 2007).

A metodologia de revisão sistemática pode ser dividida em quatro fases: definição da estratégia de busca; estabelecimento de critérios de inclusão e exclusão; leitura e fichamento; e análise e escrita da revisão (COUTINHO; MIRANDA-RIBEIRO, 2014).

Neste trabalho, em particular, utiliza-se a estratégia similar à adotada por Guedes et al., (2011), na qual parte de uma pergunta de pesquisa e, com base nela, busca identificar artigos. A fonte de dados utilizada foi o portal Periódicos da Capes, biblioteca virtual que reúne e disponibiliza os estudos de instituições de ensino e pesquisa no Brasil e produção científica internacional.

\footnotetext{
$\overline{5}$ Para mais detalhes, ver Law e Philp (2002).
} 
Como estratégia de busca para os dados (textos) foram utilizados os seguintes descritores em inglês (e português): wage, income, occupation, sexual orientation, gay, homossexual, lesbian, labor market, labor supply e discrimination (renda, ocupação, orientação sexual, homossexual, gay, lésbica, mercado de trabalho, oferta de trabalho e discriminação). ${ }^{6}$ Como critério de inclusão, optou-se por analisar somente artigos publicados em periódicos, com exceção de quatro trabalhos internacionais, em razão de sua importância na literatura (ADAM, 1981; ZAVODNY, 2007; PLUG; BERKHOUT, 2008; CALANDRINO, 1999). ${ }^{7}$

A partir da combinação dos descritores de orientação sexual com os indicadores do mercado de trabalho, foram selecionados 46 artigos. Em seguida, a partir da análise do título e resumo, foi possível verificar o alinhamento com o tema da pesquisa.

\section{Análise e discussão dos resultados}

Nos artigos analisados, foram observados 12 diferentes países e um para a OCDE, sendo eles: Estados Unidos (20), Brasil (4), Reino Unido (4), Canadá (4), Grécia (3), Suécia (3), Austrália (2), Alemanha (1), Áustria (1), França (1), Holanda (1) e Turquia (1). Tais trabalhos abrangem um período de 40 anos (1981 até 2021).

Avanços nos direitos civis e maior possibilidade de identificar indivíduos que apresentam preferência homossexual e bissexual, em várias nações do mundo, permitiram o desenvolvimento da literatura que tem estudado os impactos da orientação sexual nos rendimentos salariais. Por outro lado, as limitações de dados ainda restringem análises de como características socioeconômicas reverberam na relação entre orientação sexual e mercado de trabalho.

Adicionalmente, deve-se atentar que inferências e conclusões com base na população e nos cenários analisados de cada estudo não podem ser generalizadas para outras populações e contextos, mesmo diante de evidências de discriminação e relatos robustos de insatisfação no trabalho daqueles declarados homossexuais (DRYDAKIS, 2014b).

\section{As formas de identificação da orientação sexual}

As definições de orientação sexual seguem restrições baseadas no fato de que essas características não são facilmente observadas no indivíduo como outros aspectos marcados por fenótipos, tais como raça e sexo.

Dos 46 trabalhos analisados, ${ }^{8}$ destaca-se a predominância das uniões consensuais (coabitação) como forma de identificação, com um total de 22. A segunda identificação mais predominante, observada em nove estudos, se deu a partir de perguntas diretas a adultos sobre sua orientação sexual, conhecida na literatura como autodeclaração. Comportamento

\footnotetext{
${ }^{6}$ Ver Apêndice A, para mais detalhes.

${ }^{7}$ Para evitar duplicidade de análise, quatro artigos foram excluídos dessa revisão sem perda de consistência na avaliação dos resultados.

8 O Apêndice B apresenta uma sumarização.
} 
e o uso de experimentos apresentaram um total de sete artigos cada um. Este último, também denominado de militância, constitui experimentos nos quais se enviam currículos a empresas a fim de simular um processo de contratação. ${ }^{9}$

A identificação da orientação sexual por meio da união consensual, utilizando dados de registro civil, permite dirimir eventuais erros de medida no quantitativo de casais homossexuais em decorrência dos seus incentivos de se inscreverem nesses cadastros por conta da maior facilidade de adoção, guarda de filhos e direitos de herança (AHMED; HAMMARSTEDT, 2010).

No entanto, é importante ressaltar que cada identificação pode apresentar imprecisões, levando a possíveis erros de mensuração (UENO; ROACH; PENA-TALAMANTES, 2013). De fato, estudos que fizeram uso da identificação coabitação e comportamento apresentando evidências de vantagens nos rendimentos das lésbicas tendem a apresentar problemas de viés de seleção - somente as lésbicas de maior renda revelam sua orientação sexual (WEICHSELBAUMER, 2003).

Todavia, a identificação de parceria (coabitação) ainda é mais eficiente do que as baseadas em comportamento (PLUG; BERHOUT, 2008). Por outro lado, o uso da coabitação possui a deficiência de não incluir homossexuais que não vivem com um parceiro, além daqueles que vivem com um parceiro do mesmo sexo, mas ainda assim não revelam suas preferências (ARABSHEIBANI; MARIN; WADSWORTH, 2004). Ademais, a relutância de homens gays em revelar sua orientação sexual torna a coleta de dados ainda um problema, resultando em ausência de informação nos locais de trabalho (ALLEGRETTO; ARTHUR, 2001).

Mesmo diante de todas essas fragilidades estatísticas, o avanço na pesquisa de orientação sexual só foi possível pelo esforço dos pesquisadores em identificar uniões consensuais ao conseguir separar casais de sexo diferente de casais do mesmo sexo utilizando como referência a pessoa responsável pelo domicílio, método que se tornou factível somente a partir do censo americano de $1990 .^{10}$

De forma geral, esses trabalhos fizeram uso de pesquisas domiciliares que apresentam representatividade estatística nacional da população, analisando os diferenciais de salário entre casais heterossexuais e homossexuais e revelando perdas salariais para homens gays e ganhos, acima da média, para mulheres lésbicas, quando ambos são comparados com suas contrapartes sexuais. ${ }^{11}$

Uma grande vantagem de identificar a orientação sexual por meio da autodeclaração é a maior percentagem de homossexuais dentro da amostra. Nesta revisão sistemática,

\footnotetext{
${ }^{9}$ Apenas Akerlof e Kranton (2000) não abordam de forma direta a identificação da orientação sexual e sim como forma de identidade, definida como o conjunto de fatores que caracterizam os indivíduos em sua categoria social.

${ }^{10}$ Klawitter e Flatt (1998), Allegretto e Arthur (2001) e Clain e Leppel (2001) utilizaram dados do censo americano de 1990 e Black, Sanders e Taylor (2007), Jepsen (2007), Antecol, Jong e Steinberger (2008) e Antecol e Steinberger (2013) dados do censo americano de 2000.

${ }^{11}$ Estudos mais recentes vêm apresentando salários equivalentes ou mesmo superiores de homens gays quando comparados com os heterossexuais, enquanto as mulheres lésbicas apresentam ganhos mais baixos em comparação com as heterossexuais (DRYDAKIS; ZIMMERMANN, 2021).
} 
nove trabalhos (CARPENTER, 2005, 2008a, 2008b; FRANK, 2006; PLUG; BERKHOUT, 2008; DRYDAKIS, 2014a; OZTURK, 2011; DILMAGHANI, 2017; PRESTON; BIRCH; TIMMING, 2020) fizeram uso desse método, sendo possível identificar não somente gays e lésbicas, mas também bissexuais.

Adicionalmente, outra vantagem é a possibilidade de separar efeitos discriminatórios dos efeitos de seleção, o que permite melhorar a interpretação das estimativas concernentes aos ganhos salariais (PLUG; BERKHOUT, 2008).

Esse tipo de identificação utiliza amostragens bola de neve, método que consiste em sondagens e entrevistas por meio do recrutamento dos entrevistados em um espaço social no qual os potenciais participantes apresentam a vantagem do anonimato sobre sua sexualidade, a fim de evitar consequências pessoais onerosas. No processo de entrevista, o participante é solicitado a descrever se as normas sociais, leis e regulamentos e políticas próprias da empresa poderiam ser geradores de práticas homofóbicas e se a transformação de tais processos poderia acarretar desconstrução, subversão e transcendência da homofobia no local de trabalho (OZTURK, 2011).

Uma síntese dos resultados que se valeram desse tipo de identificação, além de reforçar salários desfavoráveis dos homens gays, observou também dificuldades de inserção no mercado de trabalho para mulheres lésbicas. De fato, jovens lésbicas, além de renda pessoal mais baixa, apresentaram probabilidade significativa maior de assédio no trabalho, dificuldade para encontrar emprego e maior insatisfação quando empregadas (CARPENTER, 2008b). ${ }^{12}$

Do total de artigos, sete utilizaram definição comportamental (BADGETT, 1995; CALANDRINO, 1999; BERG; LIEN, 2002; BLACK et al., 2003; BLANDFORD, 2003; ZAVODNY, 2007; UENO; ROACH; PEÑA-TALAMANTES, 2013).

A identificação da orientação sexual por meio do comportamento dos entrevistados ocorreu principalmente utilizando a base de dados da General Social Survey (GSS) nos Estados Unidos. Dos sete artigos aqui listados, cinco fizeram uso dessa base de dados. A GSS não pergunta diretamente a orientação sexual dos indivíduos, mas contém informações das experiências sexuais que podem ser associadas a comportamento gay, lésbico ou bissexual.

De forma mais específica, a GSS pergunta aos entrevistados se eles se relacionaram com pelo menos um parceiro do mesmo sexo desde os 18 anos de idade. No caso de resposta afirmativa, podem-se utilizar quatro métricas para medição do comportamento gay/ lésbico/bissexual: um ou mais parceiros do mesmo sexo; mais de um parceiro do mesmo sexo; pelo menos o mesmo número de parceiros do mesmo sexo e do sexo oposto; e mais de um parceiro do mesmo sexo, ou pelo menos o mesmo número de parceiros do mesmo sexo e do sexo oposto.

\footnotetext{
12 Em Carpenter (2008a), as lésbicas apresentam vantagens salariais, tendo Preston, Birch e Timming (2020) encontrado salários equivalentes entre homens gays e heterossexuais em todos os pontos da distribuição.
} 
Badgett (1995) é o trabalho seminal e serviu de referência para os demais, utilizando os anos de 1989, 1990 e 1991 da GSS. Os resultados estimados revelaram que homens gays e bissexuais ganham entre $11 \%$ e $27 \%$ a menos que seus pares heterossexuais, ao passo que não foram obtidos resultados estatisticamente significantes para mulheres lésbicas e bissexuais com relação às suas contrapartes heterossexuais.

Em todos os demais trabalhos que também fizeram uso da GSS, homens gays apresentaram desvantagens salariais quando comparados com os homens heterossexuais, ao passo que as lésbicas tiveram rendimentos acima com relação às heterossexuais. ${ }^{13}$ Esse padrão de perdas salariais para gays e ganhos para lésbicas se repete em Calandrino (1999), que fez uso da National Child Development Study do Reino Unido.

0 último método de identificação observado nessa revisão sistemática foi a militância. Ao todo, foram encontrados sete artigos (ADAM, 1981; WEICHSELBAUMER, 2003; DRYDAKIS, 2009, 2011, 2015; AHMED; HAMMARSTEDT; ANDERSON, 2013b; FLAGE, 2019) que se basearam em experimentos de envio de currículos a empresas para que fosse possível observar discriminação no processo de contratação.

Este método, conhecido como teste de correspondência, segue a metodologia de Riach e Rich (2002) e consiste na equivalência entre pelo menos dois indivíduos no que diz respeito às características de raça, idade, capital humano e status matrimonial. No entanto, esses pares possuem uma diferença: apesar de não haver menção quanto à orientação sexual nos currículos, um deles contém informação pessoal sobre voluntariado em instituição pró-direito LGBT ou algum indicativo de militância nessa causa. Nesse contexto, tal rótulo traduz que o dono do currículo comunique implicitamente sua orientação sexual.

0 trabalho seminal de Adam (1981) utilizou esse teste ao procurar observar a discriminação no processo de contratação para cargos em firmas de advocacia no Canadá. Assim, currículos idênticos, diferenciados apenas por sexo e orientação sexual, foram enviados a escritórios na cidade de Ontário em solicitação a um cargo de articulação.

Similarmente, investigou-se a existência de discriminação contra mulheres lésbicas no mercado de trabalho austríaco via testes de correspondência que atendessem aos padrões do país, mediante elaboração de um curriculum vitae, falso relatório escolar e uma fotografia. Elas foram rotuladas com informações de atividades que indicavam engajamento pessoal em movimentos organizacionais em prol de homossexuais, mas que não estivessem em conflito com sua dedicação ao trabalho. Em contraposição, como forma de sinalizar semelhante consciência social, as mulheres heterossexuais foram declaradas

\footnotetext{
$\overline{13}$ Berg e Lien (2002) ampliaram o tamanho da amostra da GSS ao utilizarem os anos de 1991 a 1996, encontrando resultados similares aos de Badgett (1995) para homens gays com relação aos heterossexuais (salários de $22 \%$ a menos); em contrapartida, as lésbicas apresentaram ganhos de $30 \%$ a mais quando comparadas às mulheres heterossexuais. Já Blandford (2003) ampliou ainda mais a base de dados da GSS ao utilizar os anos de 1989 a 1996, com resultados na mesma direção de Berg e Lien (2002), mas com magnitudes diferentes. Nesse caso, homens gays e bissexuais apresentaram desvantagens que variavam de $-30 \%$ a $-32 \%$ em relação aos pares heterossexuais, enquanto as lésbicas e bissexuais apresentaram ganhos de $17 \%$ a $23 \%$ com relação às mulheres heterossexuais. Black et al. (2003) utilizaram os mesmos anos de Blandford (2003), mas obtiveram estimativas bem diferentes: perdas salarias para gays entre $-14 \%$ e $-16 \%$ e ganhos para lésbicas entre $20 \%$ e $34 \%$. Zavodny (2007) não apresentou diferenças salariais em ambos os casos.
} 
voluntárias em instituições sem fins lucrativos e que prestassem assistência a crianças em idade escolar e com dificuldades em aprendizagem (WEICHSELBAUMER, 2003).

Em outro experimento, foi analisada a discriminação de gays em comparação com heterossexuais em candidatos imaginários ao mesmo emprego e com similar nível de capital humano a partir do envio de cartas de apresentação e curriculum vitae. Uma das inovações desse trabalho foi investigar ocupações de baixa qualificação e jovens trabalhadores do setor privado, em que se espera maior risco de discriminação. As qualificações e apresentações foram feitas considerando dois candidatos fictícios idênticos em todas as características relevantes para o emprego, distinguidos apenas pela orientação sexual. As evidências revelam que os requerentes gays são claramente discriminados em buscas idênticas de trabalho, além de terem de gastar mais tempo, esforços e recursos do que os homens heterossexuais para obter uma entrevista (DRYDAKIS, 2009).

Já em um experimento de campo com perspectivas de contratação, observou-se que mulheres lésbicas enfrentam discriminação a partir de uma probabilidade de receberem um convite para uma entrevista $27,7 \%$ menor do que candidatas mulheres heterossexuais (DRYDAKIS, 2011).

Drydakis (2015) foi mais adiante no uso do teste de correspondência ao utilizar currículos não fictícios de alunos de 12 universidades do Reino Unido. Os discentes da amostra (britânicos, solteiros) cursavam o terceiro ano de algum dos cursos predefinidos pelo autor (economia, psicologia ou educação). Assim, pareou estudantes que eram membros de algum movimento LGBT com estudantes sem nenhum tipo de relação com tal movimento, mas que tinham características relevantes para serem comparados.

No primeiro experimento sueco, foram enviados currículos com pedidos de emprego para cerca de quatro mil empregadores em dez diferentes ocupações. Não obstante ser um país caracterizado entre os mais liberais e tolerantes do mundo, gays e lésbicas tiveram problemas de inserção no mercado de trabalho. Uma hipótese consubstanciada nesse trabalho foi a menor probabilidade de ocorrência de os candidatos gays, em relação aos heterossexuais masculinos, estarem inseridos em ocupações dominadas por homens, assim como candidatas lésbicas terem menor probabilidade do que candidatas heterossexuais femininas em ocupações dominadas por mulheres (AHMED; HAMMARSTEDT; ANDERSON, 2013b).

De forma mais abrangente, foram compilados dados de 11 estudos conduzidos em oito países da OCDE representando mais de 36 mil pedidos de casais fictícios homossexuais e heterossexuais via $e$-mail ou telefone para aluguel de apartamento. Para que não configurasse como parte de um teste, todas as características essenciais, como experiência, qualificação e faixa salarial, foram pareadas identicamente, de modo que os casais diferissem apenas quanto à orientação sexual. Os resultados mostram que homens gays apresentaram $10 \%$ menos de probabilidade de serem convidados pelos proprietários para visita. No caso das mulheres, não foram observadas diferenças entre casais de lésbicas e de heterossexuais (FLAGE, 2019). 
Os resultados desses experimentos revelam que, não obstante as proteções legislativas e avanços nos direitos civis nos países desenvolvidos, as minorias sexuais, quando comparadas às suas contrapartes sexuais, ainda apresentam elevado grau de discriminação não somente na inserção do mercado de trabalho, mas também como potenciais inquilinos.

Diferenciais de rendimentos no mercado de trabalho com base na literatura de orientação sexual

Nesta subseção, os artigos foram analisados com base na variável dependente. Dentre os 46 artigos, 27 analisaram os diferenciais de ganhos e/ou perdas salariais por meio dos rendimentos mensais e anuais, utilizando a equação de Mincer (1964). ${ }^{14}$ Outra variável observada, com um total de sete trabalhos, foi a taxa de convite e entrevista; a variável distribuição do tempo e oferta de trabalho apresentou um total de cinco. Outras sete variáveis também foram identificadas, tendo cada uma apenas um trabalho catalogado. 0 Quadro 1 resume os resultados.

QUADRO 1

Trabalhos acadêmicos sobre orientação sexual e categorizados pela variável dependente

\begin{tabular}{|lc|}
\hline \multicolumn{1}{|c}{ Variável dependente } & Quantidade de trabalhos \\
\hline Renda & 27 \\
Taxa de convite e entrevista & 7 \\
Distribuição do tempo e oferta de trabalho & 5 \\
Produção familiar & 1 \\
Satisfação no trabalho & 1 \\
Concentração gay & 1 \\
Tipicidade da ocupação & 1 \\
Identidade & 1 \\
Local de trabalho & 1 \\
Bem-estar & 1 \\
\hline
\end{tabular}

Fonte: Elaboração dos autores.

No que corresponde à variável renda, os 27 artigos datam de 1995 a 2021, abrangendo diferentes países. Entre os principais resultados, destacam-se diferenças salariais desfavoráveis aos homens gays vis-à-vis os homens heterossexuais, com perdas estimadas entre $-3 \%$ e $-32 \%$; no caso das lésbicas, quando comparadas às mulheres heterossexuais, é observada uma vantagem nos seus ganhos entre 3\% e $34 \%$.

Nas primeiras estimativas para a economia americana, utilizando o censo de 1990 , revelou-se que a existência de políticas antidiscriminatórias determinadas por estados, cidades ou condados não define diferenciais salariais entre homossexuais e heterossexuais (KLAWITTER; FLATT, 1998).

\footnotetext{
${ }^{14}$ A equação de salário foi originalmente deduzida por Mincer (1974) como forma de estabelecer uma relação causal ao longo do ciclo de vida do trabalhador entre rendimentos ganhos no mercado de trabalho e um conjunto de variáveis explicativas (educação, experiência, experiência ao quadrado, entre outras).
} 
Por sua vez, o uso de variáveis que captam o estado de saúde dos indivíduos tende a dirimir viés nos resultados, na medida em que eleva o número de variáveis explicativas nas estimações. Não obstante, as evidências foram de que os gays ainda apresentam salários menores em relação a homens heterossexuais, enquanto as lésbicas apresentam ganhos quando comparadas às mulheres heterossexuais (CLAIN; LEPPEL, 2001).

Por sua vez, dados da GSS encontram suporte para a hipótese de Becker (1991), segundo a qual diferenciais nos salários podem ser resultantes da especialização dentro das famílias e decisões de acumulação de capital humano, considerando que as lésbicas são mais propensas à especialização no mercado de trabalho, além de apresentarem maior dedicação às atividades mercantis (BLACK et al., 2003).

Em contrapartida, dados do censo de 2000 dos EUA não dão suporte às diferenças de especialização doméstica como explicação para o prêmio salarial de lésbicas (JEPSEN, 2007). Outros trabalhos também observaram ausência para a hipótese da especialização domiciliar, além de atentarem para possíveis problemas em amostras que agrupam minorias por conta das diferenças entre homossexuais e bissexuais (CARPENTER, 2005).

Por outro lado, dados do censo americano de 2000 também revelaram que o diferencial de capital humano e a busca por salários mais elevados em razão da maior vulnerabilidade econômica e social são fatores determinantes para a vantagem salarial das lésbicas vis-à-vis as mulheres heterossexuais. De fato, por essas razões, a tipicidade ocupacional pode explicar até $60 \%$ nos seus ganhos (ANTECOL; JONG; STEINBERGER, 2008).

Estudos mais recentes atentam que, mesmo diante das rápidas mudanças sociais e institucionais nos EUA, a partir da segunda década do século XXI, a dinâmica do mercado de trabalho para as lésbicas pode ter mudado, principalmente no caso das jovens coabitantes, grupo particularmente mais vulnerável da população. Com efeito, enquanto lésbicas mais velhas continuam a ter leves vantagens nos seus ganhos, as jovens com menos de 45 anos apresentam penalidade salarial de até $24 \%$ (MARTELL, 2020).

No Reino Unido, foi observado que a ausência de algumas variáveis de controle em razão da omissão de resposta dos entrevistados, aliada à pequena quantidade de observações, resultou em dificuldade nas estimações das regressões, apesar de várias especificações utilizadas (CALANDRINO, 1999).

Em uma diferente perspectiva, foram agrupados dados de funcionários de forma anônima utilizando características de salário, experiência, ocupação, idade, raça, além do status parental, abertura quanto à sexualidade e percepções sobre discriminação, assédio e "conforto" no ambiente de trabalho. Nesse caso, as evidências são de efeitos de teto de vidro ("glass celing") nos rendimentos para gays/bissexuais quando comparados às mulheres heterossexuais (FRANK, 2006).

Estudo no território canadense, a partir da Canadian Community Health Survey (CHCS), corrobora os resultados para a economia americana ao revelar rendimentos $12 \%$ menores de homens gays, quando comparados aos heterossexuais, e prêmio salarial de $15 \%$ para 
mulheres lésbicas com relação às heterossexuais, após o controle nas diferenças demográficas, em educação e localidade (CARPENTER, 2008a).

Por outro lado, dados recentes para o Canadá têm destacado ganhos salariais para gays superiores aos de homens heterossexuais, além de maiores prêmios salariais para lésbicas, como resultado da sua maior quantidade de horas trabalhadas (DILMAGHANI, 2017).

Pode-se também destacar que fatores como melhora nos níveis de escolaridade, maior desenvolvimento institucional por meio de políticas antidiscriminação e reconhecimento legal do casamento de pessoas do mesmo sexo têm afetado a estrutura salarial em todos os pontos da distribuição, tanto no setor público como no privado, levando a uma equivalência de ganhos entre gays e heterossexuais nos dados da Income and Labor Dynamics in Australia (HILDA) de 2010-2012 e 2015-2017 (PRESTON; BIRCH; TIMMING, 2020).

No que tange às lésbicas, é importante ressaltar que nem todas as evidências apresentam resultados favoráveis, principalmente quando se observam variáveis não pecuniárias. Dados referentes a jovens australianas revelaram que as lésbicas são mais assediadas em ambiente de trabalho e apresentam maior taxa de insatisfação com o emprego e maior dificuldade em busca por ocupação (CARPENTER, 2008b).

Em consonância com esses resultados, existem evidências de práticas discriminatórias na França, seja pela especificidade da homofobia, seja por estereótipos associados com a homossexualidade masculina e feminina (LAURENT; MIHOUBI, 2012).

$\mathrm{Na}$ Alemanha, também foram encontradas evidências de que homens gays sofrem mais hostilidade do que lésbicas e quanto mais esses primeiros ocupam posições de poder, mais negativamente são afetados por mecanismos discriminatórios no mercado de trabalho (HUMPERT, 2016).

Na Suécia, os resultados estão conforme a maior parte da literatura americana: gays sofrem perdas salariais em relação aos seus pares heterossexuais e lésbicas têm vantagens nos seus retornos quando comparadas a mulheres heterossexuais. Esses diferenciais salariais prevalecem mais no setor privado que no público, com indícios de que homens gays enfrentam mais obstáculos para progressão nas suas atividades profissionais (AHMED; ANDERSSON; HAMMARSTEDT, 2013a).

No Brasil, dados para o censo demográfico de 2010 realizado pelo Instituto Brasileiro de Geografia e Estatística (IBGE), primeiro recenseamento do país que permitiu identificar casais a partir da orientação sexual, não indicaram padrões sistemáticos, mas diferenças estatisticamente significativas a favor dos casais do mesmo sexo. De maneira mais específica, na comparação com casais heterossexuais, destacam-se ganhos, em média, de $25 \%$ a mais para casais gays e de $13 \%$ a mais entre as lésbicas, nas estimações que corrigem por seletividade amostral. No entanto, Suliano et al. (2016) ressaltam que o contexto social brasileiro pode levar à maior disposição e motivação de pessoas com maior nível de escolaridade revelarem de forma mais espontânea suas preferências sexuais.

Mais recentemente, dados da Pesquisa Nacional de Saúde (PNS) do IBGE (2013) não apresentaram diferenças estatísticas em termos de salários entre homens gays vis-à-vis os 
homens heterossexuais. Para as mulheres, esses resultados se repetem quando se utiliza o método de Heckman em dois estágios e não se controla pelas medidas antropométricas; já o uso dos controles de altura e peso nas estimativas do heckit apresentaram ganhos salariais para as lésbicas em torno de 22,5\% (SULIANO; JESUS FILHO; IRFFI, 2021). Por sua vez, a utilização de uma generalização do método de decomposição de Oaxaca (1973) e Blinder (1973), com base em regressões de função de influência recentrada (FIR) proposto por Firpo, Fortin e Lemieux (2007), a partir dos dados da Pesquisa Nacional por Amostra de Domicílios Contínua (PNAD Contínua) de 2012 a 2016 do IBGE, apresentou resultados favoráveis aos homossexuais, além de ausência de efeitos discriminatórios no âmbito do mercado de trabalho (SULIANO; CAVALCANTE; RODRIGUES, 2021).

A segunda variável dependente mais frequente observada foi a taxa de convite e entrevista, que é simetricamente igual à identificação da orientação sexual militância. Como já descrito, esse é um método de experimento de envio de currículos a empresas mediante um teste de correspondência com pelo menos dois indivíduos com características similares, em que um deles contém informações sobre voluntariado em instituição LGBT ou algum indicativo de militância nessa causa, permitindo, assim, rotular sua orientação sexual. ${ }^{15}$

A distribuição do tempo e a oferta de trabalho foram a terceira variável dependente com maior frequência catalogada, com um total de cinco artigos, sendo quatro deles referentes ao mercado de trabalho americano e um para o brasileiro (TEBALDI; ELMSLIE, 2007; ANTECOL; STEINBERGER, 2013; MARTELL; RONCOLATO, 2016; JACINTO et al., 2017; HOFMARCHER; PLUG, 2021).

Entre os principais resultados dessa variável, pode-se destacar que a presença de filhos exerce influência no número de horas de trabalho ofertadas, principalmente entre as mulheres, seja o casal lésbico ou heterossexual. Em termos técnicos, foram observadas evidências na elasticidade do número de horas trabalhadas com relação ao número de filhos ou quantas horas adicionais podem ser despendidas pelas mulheres no mercado de trabalho considerando o total da prole.

Dados do Current Population Survey (CPS), de 2001, revelaram que mulheres com dependentes fornecem menos horas de trabalho por semana, sejam elas lésbicas ou heterossexuais casadas; para os homens, a presença de dependentes na família tem um efeito positivo na oferta de mão de obra dos heterossexuais e redução das horas trabalhadas por semana entre os homossexuais (TEBALDI; ELMSLIE, 2007).

Para as lésbicas, destacam-se casais compostos por provedoras primárias (aquelas que se especializam na produção de mercado) e assalariadas secundárias (aquelas que se especializam na produção doméstica), tendo a presença de crianças na família efeitos nas diferenças de quantidade de trabalho ofertada (ANTECOL; STEINBERGER, 2013).

0 impacto do poder de barganha e distribuição do tempo medido em trabalho doméstico, lazer e atividades mercantis forneceu evidências de que lésbicas sem filhos

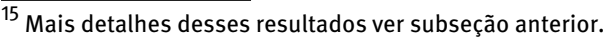


gastam menos tempo nos afazeres do lar do que as mulheres heterossexuais que vivem com crianças, reforçando o ainda forte poder do gênero como determinante na divisão do trabalho. Já homens homossexuais com filhos despendem, aproximadamente, uma hora e meia por dia a mais em trabalho doméstico do que homens casados heterossexuais; para os primeiros as evidências indicam que eles estão mais dispostos a adotar papéis fora do padrão tradicional (MARTELL; RONCOLATO, 2016).

Evidências mais recentes mostram que, embora casais do mesmo sexo difiram dos casais de sexo diferente na especialização doméstica (eles se especializam menos), ambos respondem igualmente a uma situação de vantagem comparativa nos ganhos quando decidem se especializar. De fato, nos dados de 2003 a 2019 da American Time Survey (ATUS), observou-se que parceiros do mesmo sexo e de sexo diferente respondem igualmente às vantagens comparativas; em termos quantitativos, independentemente da orientação sexual, isso quer dizer que o parceiro de maior renda gasta 80 minutos a mais por dia no mercado de trabalho e 40 minutos a menos no trabalho doméstico (HOFMARCHER; PLUG, 2021).

Para o Brasil, dados do censo demográfico de 2010 revelaram que a quantidade de horas de trabalho ofertadas por pessoas identificadas como homossexuais é menor. Essas evidências são condizentes com a existência de discriminação contra homens gays diante da maior dificuldade de ofertar horas de trabalho no mercado de trabalho brasileiro, embora as lésbicas, devido à inexistência de filhos, ofertam jornadas maiores de trabalho diante da menor necessidade de especialização no arranjo familiar (JACINTO et al., 2017).

Ainda podem ser destacadas as variáveis índice de concentração (BLACK et al., 2002), medidas de produção familiar (BLACK; SANDERS; TAYLOR, 2007), tipicidade da ocupação (UENO; ROACH; PEÑA-TALAMANTES, 2013), taxa de satisfação no trabalho (DRYDAKIS, 2014a) e bem-estar (DILMAGHANI, 2020).

Nos dados do censo americano de 2000, as evidências sugerem que casais do mesmo sexo se especializam menos do que casais de sexo diferente por conta ainda dos papéis tradicionais de gênero (BLACK; SANDERS; TAYLOR, 2007).

Já a alta concentração de domicílios gays em cidades de climas amenos e em áreas metropolitanas com altos custos de habitação reflete suas preferências por locais onde as atitudes com relação a eles sejam menos hostis, como a cidade de São Francisco (BLACK et al., 2002). ${ }^{16}$

É possível associar orientação sexual e tipicidade da ocupação. Com efeito, a composição de gênero varia entre ocupações em razão de homens e mulheres serem socializados para exercerem distintas ocupações por conta de julgamentos pré-concebidos, hostilidades de empregadores na contratação e métodos de recrutamento que exacerbam o viés do empregador. Nesse contexto, a tendência é de que as minorias sexuais apresentem

\footnotetext{
${ }^{16}$ Neste trabalho, utilizou-se um índice de concentração definido como a proporção da população identificada com parceiro do mesmo sexo com relação à população total.
} 
ocupações atípicas, sendo mais intenso este processo para homens do que para mulheres (UENO; ROACH; PEÑA-TALAMANTES, 2013).

No entanto, gays e lésbicas cuja orientação sexual era conhecida no local de trabalho apresentaram maior satisfação do que aqueles que não revelaram sua orientação. Os mais satisfeitos tendem a apresentar maior nivel de escolaridade do que heterossexuais e mais status social, além de serem mais abertos com relação à sua orientação sexual (DRYDAKIS, 2014a).

Ademais, o primeiro estudo que analisa a dimensão subjetiva de bem-estar relacionando o equilíbrio entre trabalho e vida pessoal, a partir de dados da Canadian General Survey (GSS), revelou que parceiros do mesmo sexo tendem a apresentar melhor satisfação com a vida do que aqueles que vivem com um parceiro de sexo diferente (DILMAGHANI, 2020).

\section{Considerações finais}

Ao fazer uso da técnica de revisão sistemática, este trabalho teve dois objetivos. Em primeiro lugar, procurou-se identificar, por meio da literatura especializada, diferentes formas de classificação da orientação sexual no âmbito do mercado de trabalho. Tendo em vista o segundo objetivo, foi analisado o mercado de trabalho a partir dos diferenciais de rendimentos, além da oferta de trabalho, a alocação de tempo entre atividade doméstica e de mercado, discriminação, ocupação, bem-estar, entre outras.

Diversos resultados emergiram desse estudo. Dos 46 trabalhos analisados, 22 fizeram uso da identificação da orientação sexual por meio da coabitação. 0 fato de as uniões consensuais aparecerem como predominantes dentre os artigos revisados é reflexo de esta fonte de dados ainda ser a mais disponível para pesquisadores na aferição de diferenciais salariais entre heterossexuais e homossexuais (ALLEGRETTO; ARTHUR, 2001).

O segundo tipo de identificação mais frequente se deu a partir de perguntas diretas a adultos sobre sua orientação sexual, conhecida na literatura como autodeclaração, totalizando nove. Comportamento e o uso de experimentos foram as outras duas formas de identificação observadas, cada uma com um total de sete artigos.

Diante desses resultados, é importante destacar que nos estudos de orientação sexual uma das fragilidades encontra-se justamente no tamanho das amostras de pessoas classificadas como homossexuais. De fato, a pequena quantidade de observações, bem como a ausência de resposta de algumas variáveis fundamentais por conta da não declaração dos entrevistados, resulta em maiores dificuldades nas estimações (CALANDRINO, 1999). Nesse problema, instituições públicas podem atuar com boas práticas e incentivo às pessoas para declararem espontaneamente suas preferências sexuais.

Outra maneira de dirimir esse problema em pesquisas futuras seria por meio da utilização de novas bases de dados existentes na ciência de dados. Para obter respostas verdadeiras, as pesquisas da internet são melhores do que as por telefone, que, por sua vez, são melhores do que as pessoais, não obstante esses métodos possam também apresentar 
problemas de seletividade. Todavia, as pessoas serão mais francas se estiverem sozinhas do que se houver outras pessoas na sala, muito embora em assuntos delicados todos os métodos de pesquisa evocarão uma quantidade substancial de informação incorreta (DAVIDOWITZ, 2018).

A presente revisão sistemática também observou diferenciais salariais desfavoráveis aos homens gays vis-à-vis os heterossexuais, com perdas estimadas que variaram entre - $3 \%$ e $-32 \%$. As perdas salariais de trabalhadores homossexuais do sexo masculino refletem práticas discriminatórias e estereotipadas (LAURENT; MIHOUBI, 2012) e inserção em ocupações dominadas por mulheres com salários mais baixos (ANTECOL; JONG; STEINBERGER, 2008).

Quanto aos diferenciais salariais entre as mulheres, a literatura catalogada revelou vantagens nos ganhos das lésbicas quando comparadas às mulheres heterossexuais, com estimações variando entre 3\% e 34\%. A crescente literatura conjectura algumas hipóteses para esse diferencial favorável, tais como mais apego ao mercado de trabalho do que suas contrapartes sexuais (BLACK; SANDERS; TAYLOR, 2007) e maior oferta de mão de obra (DILMAGHANI, 2017). Além disso, estereótipos podem levar as lésbicas a serem percebidas como menos propensas à geração de filhos e mais dedicação à carreira profissional (PEPLAU; FINGERHTT, 2004). É possível também que a perspectiva de discriminação e maior risco de vulnerabilidade social podem levá-las a um maior nível de escolaridade e elevação dos seus prêmios salariais (BADGETT, 1995).

Outro resultado consolidado, a partir dos testes de correspondência, refere-se às restrições de acesso ocupacional tanto para homens gays como para lésbicas, mesmo para a Suécia, país caracterizado entre os mais liberais e tolerantes do mundo. As evidências apresentadas revelam que a discriminação não surge em decorrência da falta de informação sobre as características do indivíduo, mas sim de preferências negativas profundamente enraizadas (FLAGE, 2019).

Outro ponto de convergência observado corresponde às decisões dos casais no que tange à oferta de trabalho, independentemente da orientação sexual, revelando, pelo menos sob o prisma econômico, escolhas compartilhadas na família. De fato, sejam lésbicas ou heterossexuais, mulheres com dependentes fornecem menos horas de trabalho por semana (TEBALDI; ELMSLIE, 2007). Adicionalmente, em termos quantitativos, seja qual for a orientação sexual do casal, o parceiro com maior renda gasta 80 minutos a mais por dia no mercado de trabalho e 40 minutos a menos no trabalho doméstico (HOFMARCHER; PLUG, 2021).

Evidências mais recentes destacam salários equivalentes ou mesmo superiores de homens gays quando comparados com os heterossexuais, enquanto as lésbicas apresentam ganhos mais baixos em relação às heterossexuais (DRYDAKIS; ZIMMERMANN, 2021). Não obstante, é importante atentar que as minorias sexuais ainda estão alocadas em ocupações atípicas em razão das hostilidades de empregadores na contratação e métodos de recrutamento viesados (UENO; ROACH; PEÑA-TALAMANTES, 2013). 
O escopo desse trabalho concentrou-se na catalogação das diferentes formas de identificação da orientação sexual e nos diferenciais de salário no âmbito do mercado de trabalho, objeto de pesquisa da maior parte da literatura empírica do referido tema. No entanto, é importante destacar o esforço das atuais pesquisas na literatura empírica em complementação às análises já abordadas e que podem servir de orientação futura para estudos no Brasil.

Por exemplo, tem-se observado que um ambiente familiar caloroso para pessoas que se identificam como lésbicas, gays e bissexuais (LGB) tende tanto a reduzir o bullying na idade escolar como proporcionar efeitos positivos de longo prazo no futuro local de trabalho (SIDIROPOULOU et al., 2020).

Pode-se também destacar uma associação positiva entre o PIB real per capita e a inclusão social de pessoas LGB. Em outras palavras, isso quer dizer que existem custos econômicos que incluem tempo de trabalho perdido, queda da produtividade, investimento insuficente em capital humano e alocação ineficiente de recursos quando os direitos legais de minorias sexuais estão suprimidos (BADGETT; WAALDIJK; RODGERS, 2019).

Assim, legislações mais rigorosas que inibam práticas homofóbicas tornam-se primordiais, não obstante os avanços legislativos alcançados em termos de união civil tanto no Brasil como em outros países. É fundamental que o ambiente profissional seja alinhado à produtividade do trabalhador e não pautado em preferências sexuais.

\section{Referências}

ADAM, B. D. Stigma and employ ability: discrimination by sex and sexual orientation in the Ontario legal profession. Canadian Review of Sociology, v. 18, n. 2, p. 216-221, 1981.

ALVES, J. E. D.; CAVENAGHI, S. M.; BARROS, L. F. W. A família DINC no Brasil: algumas características sócio-demográficas. Rio de Janeiro: Escola Nacional de Ciências Estatísticas, 2010. (Texto para Discussão, n. 30).

AHMED, A. M.; HAMMARSTEDT, M. Sexual orientation and earnings: a register data based approach to identify homosexual. Journal of Population Economics, v. 23, n. 3, p. 835-849, 2010.

AHMED, A. M.; ANDERSSON, L.; HAMMARSTEDT, M. Sexual orientation and full-time monthly earnings, by public and private sector: evidence from Swedish register data. Review of Economics of the Household, v. 11, n. 1, p. 83-108, 2013a.

AHMED, A. M.; ANDERSSON, L.; HAMMARSTEDT, M. Are gay men and lesbians discriminated against in the hiring process? Southern Economic Journal, v. 79, n. 3, p. 565-585, 2013b.

AKERLOF, G. A.; KRANTON, R. E. Economics and identity. Quarterly Journal of Economics, v. 115, n. 3, p. 715-753, ago. 2000.

ALLEGRETTO, S. A.; ARTHUR, M. M. An empirical analysis of homosexual/heterosexual male earnings differentials: unmarried and unequal? Industrial \& Labor Relations Review, v. 54, n. 3, p. 631-646, 2001.

ANTECOL, H.; JONG, A.; STEINBERGER, M. The sexual orientation wage gap: the role of occupational sorting and human capital. Industrial \& Labor Relations Review, v. 61, n. 4, p. 518-526, 2008. 
ANTECOL, H.; STEINBERGER, M. D. Labor supply differences between married heterosexual women and partnered lesbians: a semi-parametric decomposition approach. Economic Inquiry, v. 51, n. 1, p. 783-805, 2013.

ARABSHEIBANI, G. R.; MARIN, A.; WADSWORTH, J. In the pink: homosexual heterosexual wage differentials in the UK. International Journal of Manpower, v. 25, n. 3/4, p. 343-354, 2004.

BADGETT, M. V. L. The wage effects of sexual orientation discrimination. Industrial \& Labor Relations Review, v. 48, n. 4, p. 726-739, 1995.

BADGETT, M. V. L.; WAALDIJK, K.; RODGERS, Y. M. The relationship between LGBT inclusion and economic development: macro-level evidence. World Development, v. 120, p. 1-14, 2019.

BECKER, G. S. The economics of discrimination. Chicago: Economic Research Studies, 1957.

BECKER, G. S. A treatise on the family. Harvard University Press, 1991.

BERG, N.; LIEN, D. Measuring the effect of sexual orientation on income: evidence of discrimination? Contemporary Economic Policy, v. 20, n. 4, p. 394-414, 2002.

BERWANGER, O.; SUZUMURA, E. A.; BUEHLER, A. M.; OLIVEIRA, J. B. Como avaliar criticamente revisões sistemáticas e metanálises? Revista Brasileira de Terapia Intensiva, v. 19, n. 4, p. 475 480, 2007.

BLACK, D.; GATES, G.; SANDERS, S.; TAYLOR, L. Why do gay men live in San Francisco? Journal of Urban Economics, v. 51, n. 1, p. 54-76, 2002.

BLACK, D.; MAKAR, R.; SANDERS, S.; TAYLOR, L. The earnings effects of sexual orientation. Industrial \& Labor Relations Review, v. 56, n. 3, p. 449-469, 2003.

BLACK, D.; SANDERS, S.; TAYLOR, J. The economics of lesbian and gays families. Journal of Economic Perspectives, v. 21, n. 2, p. 53-70, 2007.

BLINDER, A. S. Wage discrimination: reduced form and structural estimates. The Journal of Human Resources, v. 8, n. 4, p. 436-455, 1973.

BORRILLO, D. Homofobia. História e crítica de um preconceito. Belo Horizonte: Autêntica, 2010.

BRASIL. Supremo Tribunal Federal. Arguição de Descumprimento de Preceito Fundamental n. 132, de 05 de maio de 2011. Diário Oficial da União, Brasília, DF, 2011.

CALANDRINO, M. Sexual orientation discrimination on the UK labor market. St. Antony's College, University of Oxford, 1999. (Working Paper).

CAMARANO, A. A. Introdução. In: CAMARANO, A. A. (org.). Novo regime demográfico. Uma nova relação entre população e desenvolvimento? Rio de Janeiro: Ipea, 2014.

CAMARANO, A. A.; FERNANDES, D. Mudanças nos arranjos familiares e seu impacto nas condições de vida: 1980 e 2010. In: CAMARANO, A. A. (org.). Novo regime demográfico. Uma nova relação entre população e desenvolvimento? Rio de Janeiro: Ipea, 2014.

CARPENTER, C. S. Self-reported sexual orientation and earnings: evidence from California. Industrial \& Labor Relations Review, v. 58, n. 2, p. 258-273, 2005.

CARPENTER, C. S. Sexual orientation, work, and income in Canada. Canadian Journal of Economics/Revue Canadienne D’économique, v. 41, n. 4, p. 1239-1261, 2008 a.

CARPENTER, C. S. Sexual orientation, income, and non-pecuniary economic outcomes: new evidence from young lesbians in Australia. Review of Economics of the Household, v. 6, n. 4, p. 391-408, 2008b. 
CLAIN, S. H.; LEPPEL, K. An investigation into sexual orientation discrimination as an explanation for wage differences. Applied Economics, v. 33, n. 1, p. 37-47, 2001.

COOK, C.; DIAMOND, R.; HALL, J.; LIST, J. A.; OYER, P. The gender earnings gap in the gig economy: evidence from over a million rideshare drivers. Cambridge, MA: National Bureau of Economic Research, 2018 (NBER Working Paper, 24732).

COUTINHO, R. Z.; MIRANDA-RIBEIRO, P. Religião, religiosidade e iniciação sexual na adolescência e juventude: lições de uma revisão bibliográfica sistemática de mais de meio século de pesquisas. Revista Brasileira de Estudos de População, v. 31, n. 2, p.333-365, 2014.

DAVIDOWITZ, S. S. Todo mundo mente. 0 que a internet e os dados dizem sobre quem realmente somos. Rio de Janeiro: Alta Books, 2018.

DILMAGHANI, M. Sexual orientation, labour earnings, and household income in Canada. Journal of Labor Research, v. 39, n. 1, p. 41-55, 2017.

DILMAGHANI, M. Exploring the link between sexual orientation, work-life balance satisfaction and work-life segmentation. International Journal of Manpower, v. 41, n. 6, p. 693-715, 2020.

DRYDAKIS, N. Sexual orientation discrimination in the labour market. Labour Economics, v. 16, n. 4, p. 364-372, 2009.

DRYDAKIS, N. Women's sexual orientation and labour market outcomes in Greece. Feminist Economics, v. 17, n. 1, p. 89-117, 2011.

DRYDAKIS, N. Effect of sexual orientation on job satisfaction: evidence from Greece. Industrial Relations, v. 54, n. 1, p. 162-187, 2014 a.

DRYDAKIS, N. Sexual orientation and labor market outcomes. IZA World of Labor, 111, 2014b.

DRYDAKIS, N. Sexual orientation discrimination in the United Kingdom's labour market: a field experiment. Human Relations, v. 68, n. 11, p. 1769-1796, 2015.

DRYDAKIS, N.; ZIMMERMANN, K. F. Sexual orientation, gender identity and labour market outcomes: new patterns and insights. Essen, Germany: Global Labor Organization, 2021. (GLO Discussion Paper, n. 627).

FIRPO, S.; FORTIN, N.; LEMIEUX, T. Decomposing wage distributions using recentered influence function regressions. University of British Columbia, 2007. Mimeo.

FLAGE, A. Discrimination against same-sex couples in the rental housing market, a meta-analysis. Economics Bulletin, v. 41, n. 2, p. 643-653, 2021.

FRANK, J. Gay glass ceilings. Economica, v. 73, n. 291, p. 485-508, 2006.

GOLDIN, C. Understanding the gender gap: an economic history of American women. Oxford University Press, 1990.

GOLDIN, C. A grand gender convergence: its last chapter. American Economic Review, v. 104, n. 4, p. 1091-1119, 2014.

GORISCH, P. Reconhecimento dos direitos humanos LGBT. De Stonewall à ONU. Curitiba: Appris, 2014.

GUEDES, G. R.; QUEIROZ, B. L.; BARBIERI, A. F.; VANWEY, L. K. Ciclo de vida domiciliar, ciclo do lote e mudança no uso da terra na Amazônia brasileira: revisão crítica da literatura. Revista Brasileira de Estudos de População, v. 28, n. 1, p. 231-240, 2011.

HOFFMANN, H.; LEONE, E. T. A. Participação da mulher no mercado de trabalho e desigualdade da renda domiciliar per capita no Brasil: 1981-2002. Nova Economia, v. 14, n. 2, p. 35-58, 2004. 
HOFMARCHER, T.; PLUG, E. Specialization in same-sex and different-sex couples. Labour Economics, v. 10, p. 13-18, 2021.

HUMPERT, S. Somewhere over the rainbow: sexual orientation and earnings in Germany. International Journal of Manpower, v. 37, n. 1, p. 69-98, 2016.

JACINTO, P.; FRIO, G.; UHR, D.; UHR, J. Z. Offer of work and sexual orientation: evidence of Brazil. The Empirical Economics Letters, v. 16, n. 7, p. 663-667, 2017.

JEPSEN, L. K. Comparing the earnings of cohabiting lesbians, cohabiting heterosexual women, and married women: evidence from the 2000 Census. Industrial Relations, v. 46, n. 4, p. 699727, 2007.

KLAWITTER, M. M.; FLATT, V. The effects of State and local anti-discrimination policies on earnings for gays and lesbians. Journal of Policy Analysis and Management, v. 17, n. 4, p. 658-686, 1998.

LAURENT, T.; MIHOUBI, F. Sexual orientation and wage discrimination in France: the hidden side of the rainbow. Journal of Labour Research, v. 33, n. 4, p. 487-527, 2012.

LAW, M.; PHILP, I. Systematically reviewing the evidence. In: LAW, M. Evidence-based rehabilitation: a guide to practice. Thorofare: SLACK, 2002.

LESTHAEGHE R.; VAN de KAA, D. Twee demografische transities? In: LESTHAEGHE R.; VAN de KAA, D. (ed.). Bevolking: groei en krimp. Deventer: Mens en Maatschappij, 1986. p. 9-24.

LESTHAEGHE, R.; SURKYN, J. Cultural dynamics and economic theories of fertility change. Population Development Review, v. 14, n. 1, p. 1-45, 1988.

LESTHAEGHE, R. The second demographic transition in Western countries. In: MASON, K. O.; JENSEN, A-M. Gender and family change in industrialized countries. New York: Clarendon Press, 1995. p. 17-62.

LESTHAEGHE, R. The second demographic transition: a concise overview of its development. Proceedings of the National Academy of Sciences of the United States of America, v. 111, n. 51, p. 18112-18115, 2014.

MARTELL, M. E. Age and the new lesbian earnings penalty. International Journal of Manpower, v. 41, n. 6, p. 649-670, 2020.

MARTELL, M. E.; RONCOLATO, L. The homosexual lifestyle: time use in same-sex households. Journal of Demographic Economics, v. 82, n. 4, p. 365-398, 2016.

MINCER, J. Schooling, experience and earning. New York: Columbia University Press, 1974.

NAGAMINE, R. R. V. K. Os direitos de pessoas LGBT na ONU (2000-2016). Revista Latinoamericana, n. 31, p. 28-56, 2019.

OAXACA, R. Male-female wage differentials in urban labour markets. International Economic Review, v. 14, n. 3, p. 693-709, 1973.

OLSEN, C. S. L. D. A comunidade LGBT na Dinamarca: a luta continua? A promoção dos direitos da comunidade LGBT num Estado de Bem-Estar. In: PICCHETTI, V. C. (org.). Mundo afora. Políticas de combate à violência e à discriminação contra pessoas LGBT. Brasília: Ministério das Relações Exteriores, 2015. p. 130-137.

OZTURK, M. B. Sexual orientation discrimination: exploring the experiences of lesbian, gay and bisexual employees in Turkey. Human Relations, v. 64, n. 8, p. 1099-1118, 2011.

PEPLAU, L. A.; FINGERHUT, A. The paradox of the lesbian worker. Journal of Social Issues, v. 60, p. 719-735, 2004. 
PRESTON, A.; BIRCH, E.; TIMMING, A. R. Sexual orientation and wage discrimination: evidence from Australia. International Journal of Manpower, v. 41, n. 6, p. 629-648, 2020.

PLUG, E.; BERKHOUT, P. H. G. Sexual orientation, disclosure and earnings. Bonn, Germany: Institute for the Study of Labor, 2008. (IZA Discussion Paper, n. 3290).

RIACH, P. A.; RICH, J. Field experiments of discrimination in the market place. The Economic Journal, v. 112, n. 483, p. 480-518, 2002.

SAMPAIO, R. F.; MANCINI, M. C. Estudos de revisão sistemática: um guia para síntese criteriosa da evidência científica. Revista Brasileira de Fisioterapia, v. 11, n. 1, p. 83-89, 2007.

SCORZAFAVE, L. G.; MENEZES-FILHO, N. A. Participação feminina no mercado de trabalho brasileiro: evolução e determinantes. Pesquisa e Planejamento Econômico, v. 31, n. 3 p. 441478, 2001.

SIDIROPOULOU, K.; DRYDAKIS, N.; HARVEY, B.; PARASKEVOPOULOU, A. Family support, schoolage and workplace bullying for LGB people. International Journal of Manpower, v. 41, n. 6, p. 717-730, 2020.

SULIANO, D.; IRFFI, G.; CORRÊA, M. V.; CAVACALNTE, A.; OLIVEIRA, J. Sexual orientation and wage differentials in Brazilian labour market. Economia Aplicada, v. 20, n. 3, p. 195-221, 2016.

SULIANO, D.; CAVACALNTE, A.; OLIVEIRA, J. Sexual orientation and in Brazil using unconditional quantile regression. Economia e Sociedade, v. 30, n. 1, p. 259-285, 2021.

SULIANO, D.; JESUS FILHO, J.; IRFFI, G. Sexual orientation and wage differentials using anthropometric and health measures. Estudos Econômicos, v. 51, n. 1, p. 111-142, 2021.

TRANDAFIR, M. The effect of same-sex marriage laws on different-sex marriage: evidence from the Netherlands. Groupe de Rechervhe en Économie et Développement International, v. 9, n. 23, 2012.

TEBALDI, E.; ELMSLIE, B. Sexual orientation and labour supply. Applied Economics, v. 38, n.5, p. 549-562, 2007.

UENO, K.; ROACH, T.; PENA-TALAMANTES, A. E. Sexual orientation and gender typicality of the occupation in young adulthood. Social Forces, v. 92, n. 1, p. 81-108, 2013.

WEICHSELBAUMER, D. Sexual orientation discrimination in hiring. Labour Economics, v. 10, n. 6, p. 629-642, 2003.

ZAVODNY, M. Is there a 'marriage premium' for gay men? Bonn, Germany: Institute for the Study of Labor, 2007. (IZA Discussion Paper, n. 3192).

\section{Sobre os autores}

Daniel Suliano é doutor em Economia pela Universidade Federal do Ceará (Caen/UFC). Analista de Políticas Públicas no Instituto de Pesquisa e Estratégia Econômica do Ceará (Ipece).

Guilherme Irffi é doutor em Economia pela Universidade Federal do Ceará (Caen/UFC). Professor associado no Departamento de Economia Aplicada e do Programa de Pós-Graduação em Economia da UFC.

Ana Beatriz Rêgo de Sá Barreto é mestre em Finanças pela BI Norwegian Business School. Analista de Fusões e Aquisições no Grupo Fleury. 


\title{
Endereço para correspondência
}

\author{
Daniel Suliano \\ Av. General Afonso Albuquerque Lima, s/n, Edifício Seplag, térreo, Cambeba \\ 60822-325 - Fortaleza-CE, Brasil \\ Guilherme Irffi \\ Av. da Universidade, 2762, $2^{\circ}$ andar \\ 60020-181 - Fortaleza-CE, Brasil \\ Ana Beatriz Rêgo de Sá Barreto \\ Av. General Valdomiro de Lima, 508 \\ 04344-070 - São Paulo-SP, Brasil
}

\begin{abstract}
Sexual orientation and its effects on the labor market: a study based on systematic review technique
\end{abstract}

By using the systematic review technique, this work has two objectives. First, we tried to identify different forms of classification of sexual orientation in the labor market. For our second objective, the labor market was analyzed as a channel that generates unequal income distribution through discriminatory mechanisms based on income differentials based on sexual orientation. The data source used was the Periódicos Capes. Among the results, four forms of identification of sexual orientation were observed, with consensual unions (cohabitation) having the largest number of studies followed by self-declaration, behavior and activism. Additionally, results show a salary penalty suffered by gay men compared to their sexual counterparts, a salary premium for lesbians in relation to heterosexual women and disadvantages for homosexuals in labor market insertion. Simulations in the rate of interviews reveal signs of discrimination right at the initial hiring stage. Finally, it is emphasized that even with legislation protecting sexual minorities, and in more liberal and tolerant countries, the professional environment is not completely aligned with worker productivity.

Keywords: Labor market. Sexual orientation. Homosexual.

\section{Resumen}

La orientación sexual y sus efectos en el mercado laboral: un estudio basado en técnica sistemática de revisión

Al utilizar la técnica de revisión sistemática, este trabajo tiene dos objetivos. En primer lugar, intentamos identificar diferentes formas de clasificación de la orientación sexual dentro del mercado laboral. Luego, en vistas al segundo objetivo, se analizó el mercado laboral como un canal que genera una distribución desigual del ingreso a través de mecanismos discriminatorios basados en diferenciales de ingresos por orientación sexual. La fuente de datos utilizada fue Periódicos Capes. Entre los resultados, se observaron cuatro formas de identificación de la orientación sexual, entre las que las uniones consensuales significan el mayor número de estudios, seguidas de autodeclaración, conducta y activismo. Se puede destacar la penalización salarial que sufren los hombres gays frente a sus homólogos heterosexuales, la 
prima salarial para las lesbianas en relación con las mujeres heterosexuales y las desventajas de los homosexuales en la inserción laboral en simulaciones en la tasa de convocatoria para entrevista laboral, lo que revela pistas de discriminación en la etapa inicial de contratación. Se enfatiza que, incluso en presencia de una legislación que protege a las minorías sexuales, en países más liberales y tolerantes, el entorno profesional no está completamente alineado con la productividad del trabajador.

Palabras clave: Mercado laboral. Orientación sexual. Homosexual.

Recebido para publicação em: 28/09/2020

Aceito para publicação em 18/09/2021

\section{Apêndice A - Estratégias de busca e descritores para artigos selecionados}

No portal Periódicos Capes foi aplicada uma string de busca ou equação considerando descritores nos idiomas inglês e português. A forma de equação é conectada por operadores booleanos, como, por exemplo:

Título: ("sexual orientation") OR ("wage") AND

Assunto: (labor market) OR (labor supply) OR (“discrimination*”)

$O$ uso do suporte dos operadores booleanos ( $A N D, O R, N O T$ ), bem como de caracteres especiais como asteriscos ( $\left.{ }^{\star}\right)$, aspas (" ") e coringa (?), facilita o refinamento na estratégia de busca. 


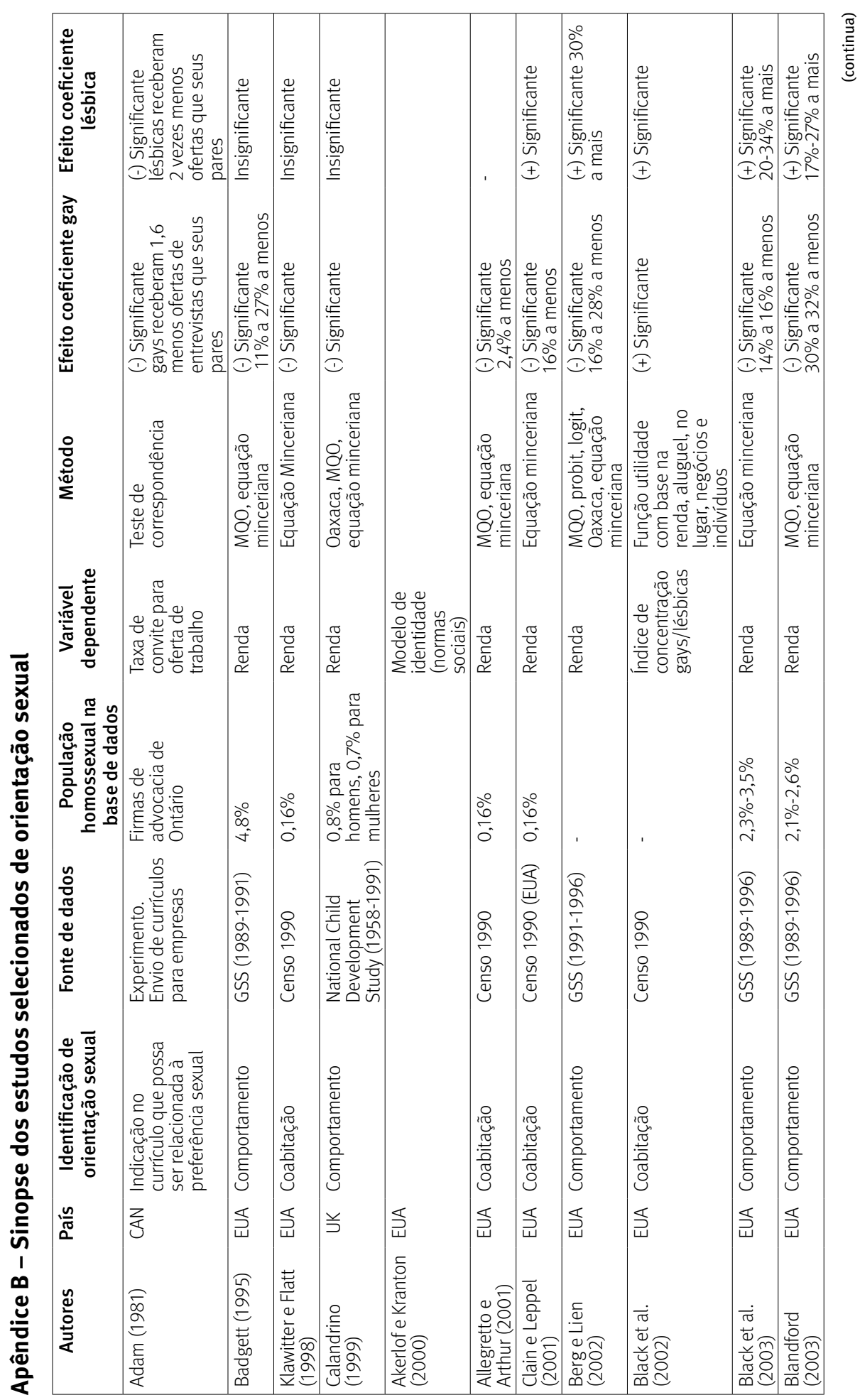




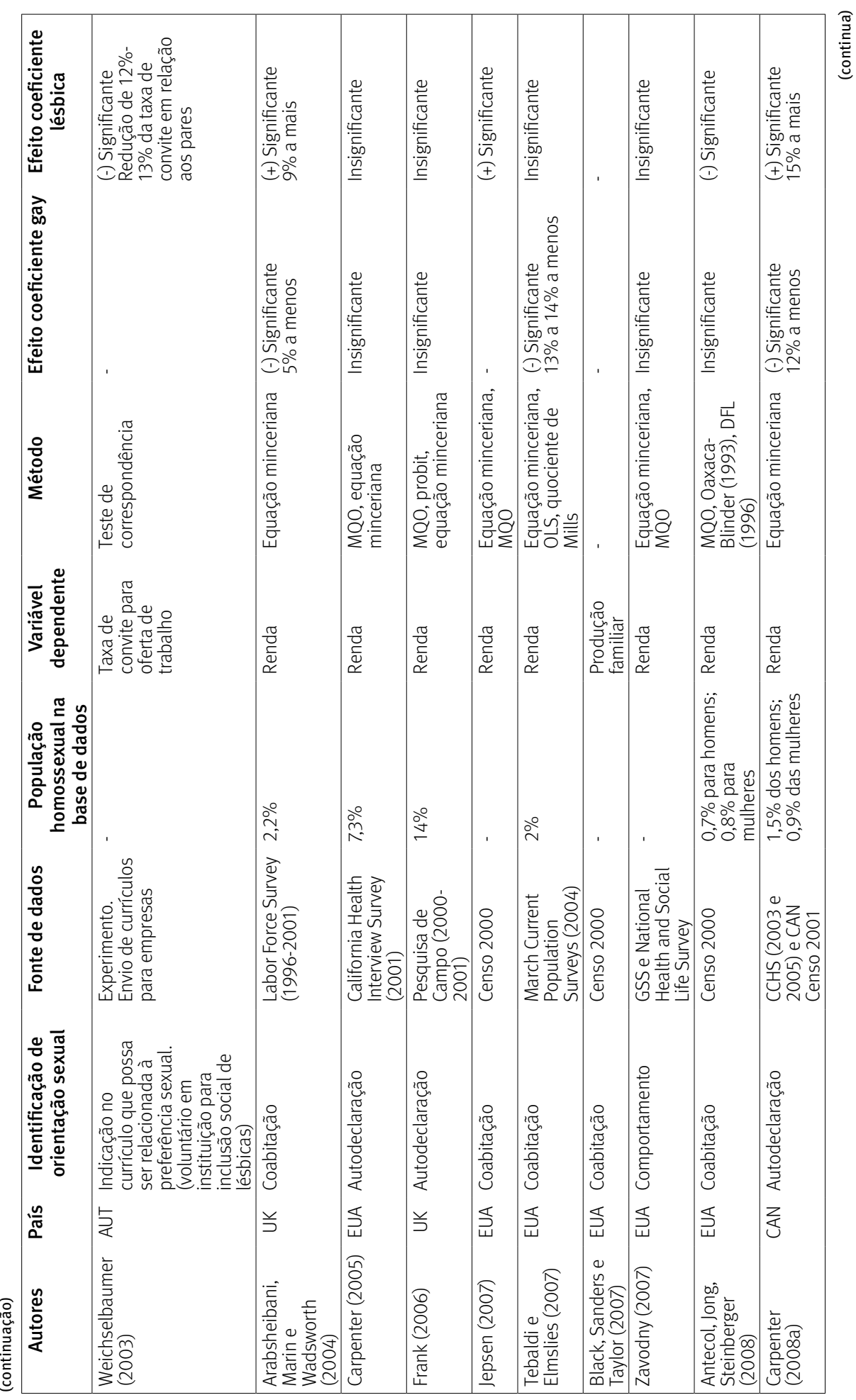




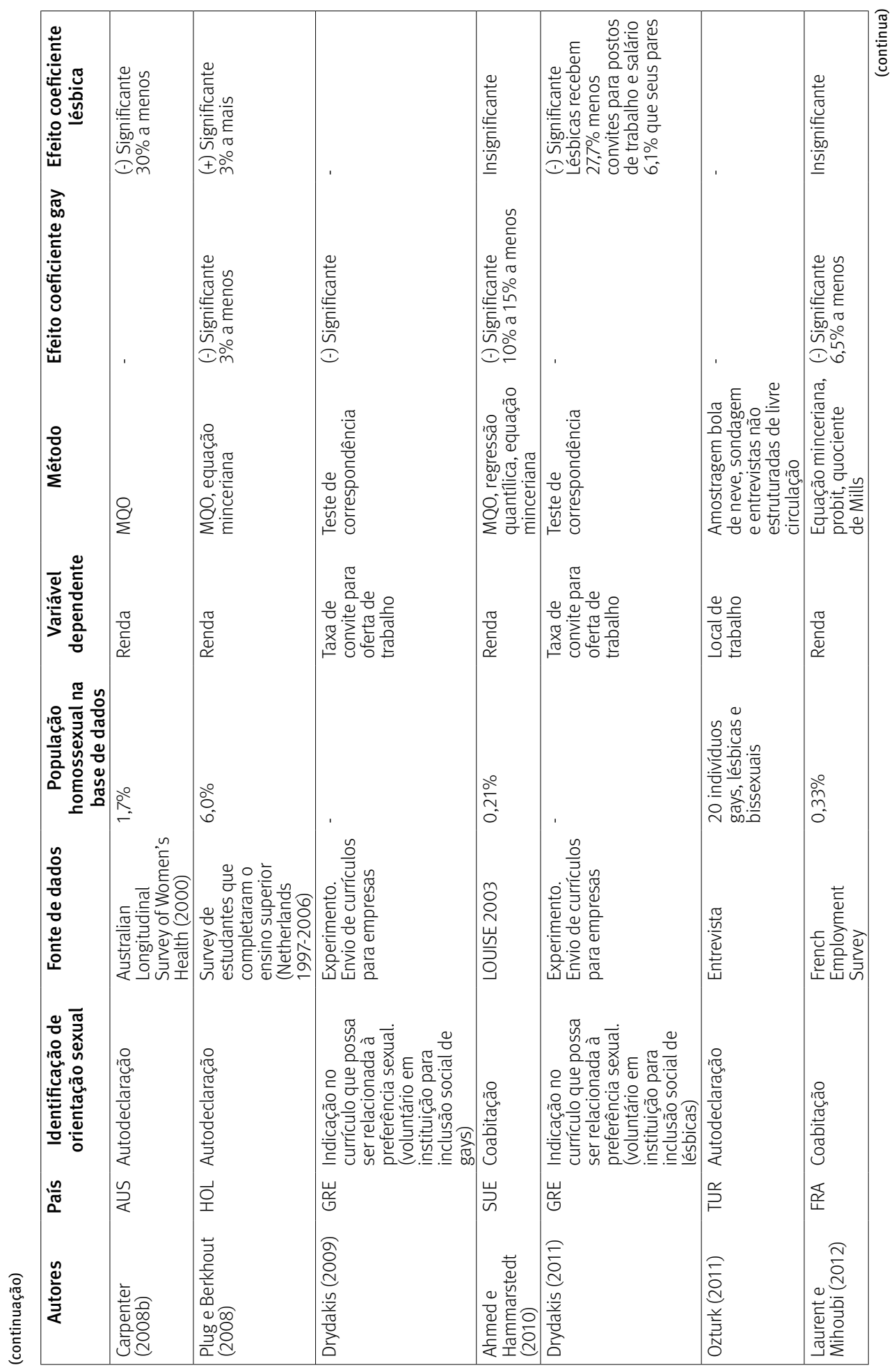




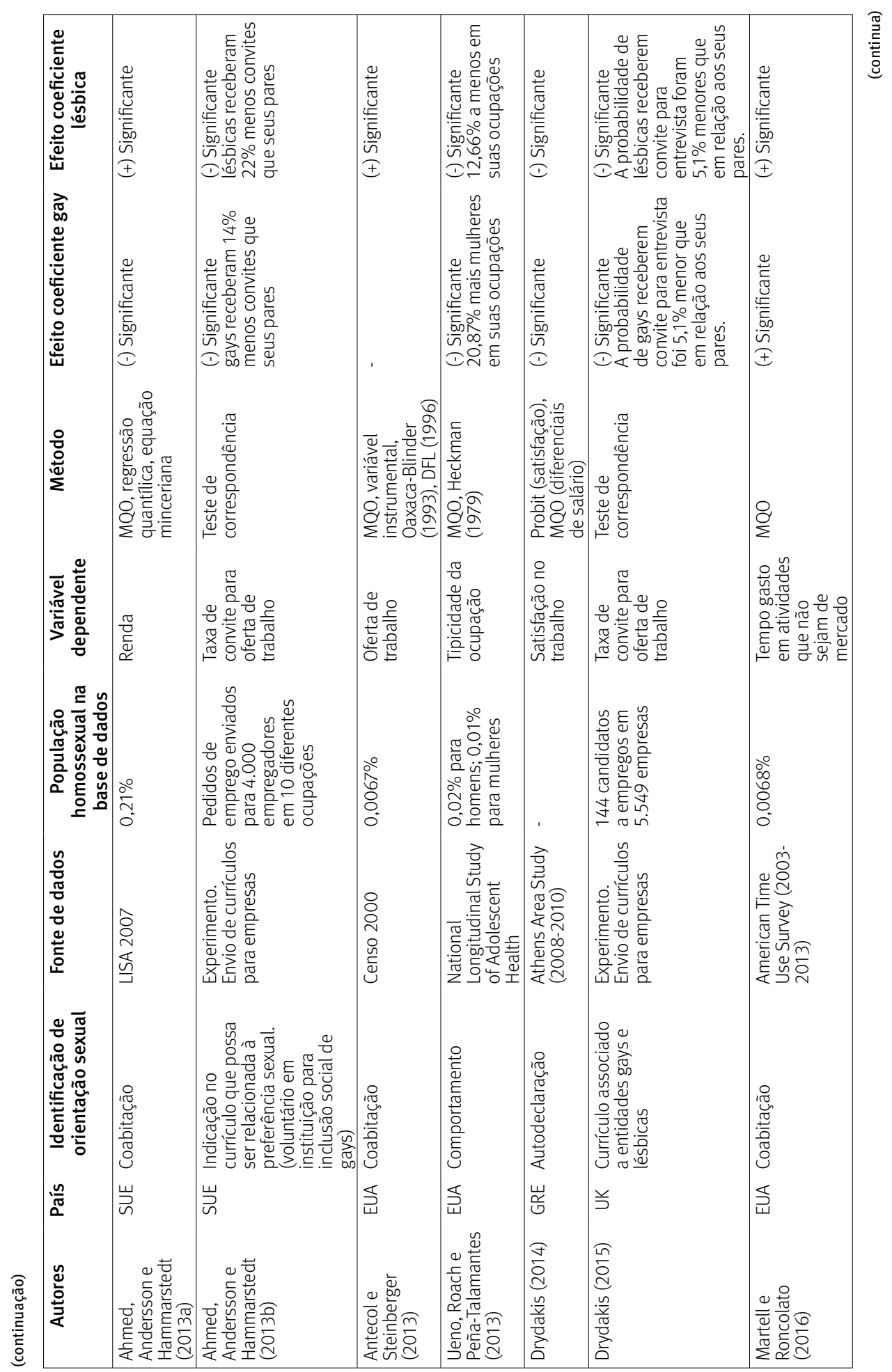




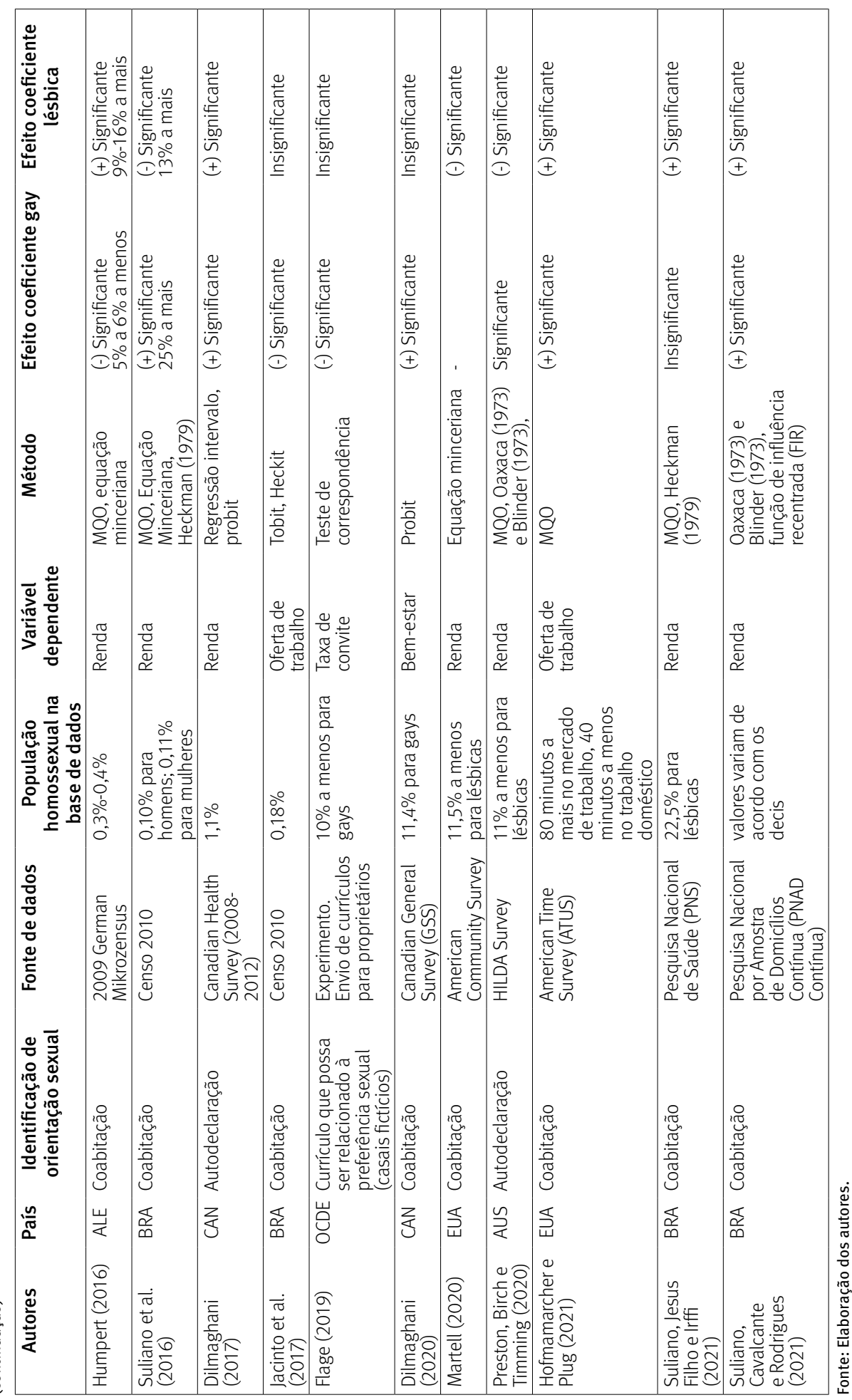

